\title{
PREVENTION OF ROUND TIMBER LATERAL CRACKING IN WOODEN HOUSE CONSTRUCTION
}

\author{
Vladimir Glukhikh¹, Anait Akopian² \\ 1,2 Saint Petersburg State University of Architecture and Civil Engineering \\ Vtoraja Krasnoarmejskaja ul. 4, St. Petersburg, Russia \\ 1 VNGlukhikh@mail.ru
}

\begin{abstract}
The article is devoted to the most widespread defect of regularized round timbers in wooden house construction, i.e. their lateral cracking in the process of further use of buildings and structures. A method is proposed to cut lateral saw kerfs in the round timber surface upon timber rounding, which almost completely excludes appearance of cracks on exposed surfaces. Saw kerfs are cut in the exterior surfaces of round timber on the opposite side of the simultaneously manufactured technological notch.

According to the results of theoretical and experimental studies, it was ascertained that the saw kerf is the main factor which excludes appearance of lateral cracking in regularized round timber. Taking into account the technological notch, the optimal depth of a saw kerf should not be more than $35 \%$ of the round timber cross-section radius.

The absence of visible lateral macro-cracks on exposed surfaces of round timber will improve the appearance of a building and prolong its service life. Macro-cracks appear at the bottom of the technological notch and at the bottom of the saw kerf which serve as stress concentrators. Such stresses occurring due to the hygroscopic moisture gradient along the round timber cross-section radius and anisotropy of wood shrinkage in points with stress concentrators can exceed the limit values upon extension in the tangential direction, wherefore macro-cracks will form in the areas with stress concentrators.
\end{abstract}

According to estimates, additional energy consumption for making a lateral saw kerf will be 1-2\%.

\section{Keywords}

Wooden house construction, technological notch, crack formation, round timber cracking.

\section{Introduction}

Industrial production of wooden houses is one of the most promising directions in the domestic housing development. Global tendencies and long-term foreign experience in the field of low-rise housing construction prove the high effectiveness of house prefabrication and its competitiveness according to such criteria as comfort and design, individuality and design simplicity, environmental friendliness and manufacturability.

However, the global crisis partially manifested in the contraction of the market of newly introduced dwelling substantially affected the production volumes of woodworking enterprises of the building sector. Development of wooden house construction is the main way to increase the internal consumption of timber products in our branch of industry.

When analyzing round timber cracking in block houses, we shall pay attention to the fact that, in most cases, macro-cracks form at the bottom of technological notch- es (Figure 1). These are macro-cracks that get out to the round timber end. The technological notch is a stress concentrator where the danger of cracking is somewhat less than in saw kerfs, however, it may be a problem. Any cut, a hollow on the round timber surface, a saw kerf form increased tensile stresses, leading to material crippling, i.e. formation of deep lateral cracks.

Thus, when selecting a point for a saw kerf, a macro-crack appearance site shall be pre-defined - it appears at the bottom of a saw kerf.

A lateral saw kerf in the non-exposed surface of round timber leads to the appearance of the second stress concentrator, which jointly with a technological notch shall provide decrease of tensile stresses on the surface of round timber upon drying out.

Any capillary porous material, including timber, starts drying out from the surface. If moisture of surface zones is below the limit of the hygroscopic property, sizes decrease and wood shrinkage occurs. However, the shrink- 
age of the round timber surface layer is impeded by its significant inner part where wood moisture is above the limit of the hygroscopic property and there is no shrinkage. As a result, the surface layer of round timber is subjected to stretching and, therefore, compresses the inner part.

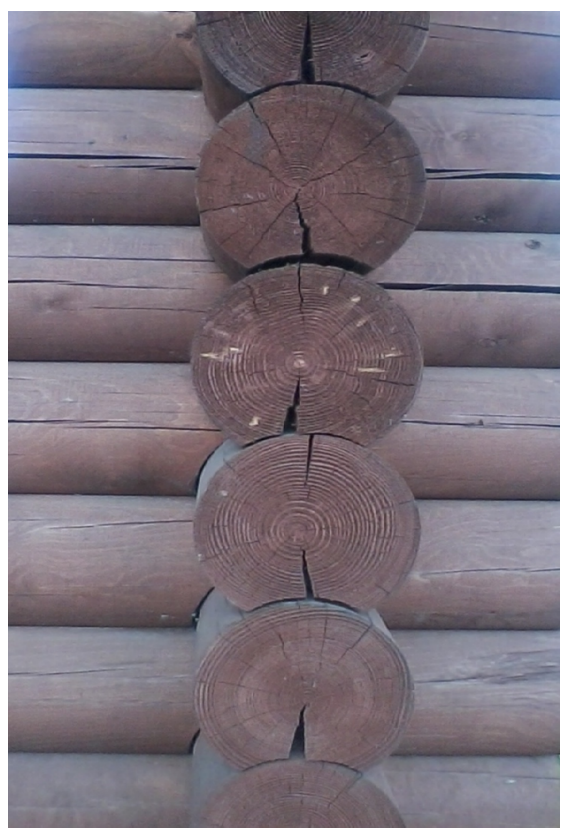

Figure 1. Crack on the surface of the technological notch

The material is subjected to the radial compression throughout the entire cross-section. In the circumferential direction, tensile stresses act on the periphery, whereas in the central zone we observe compressing stresses. In this case, the highest risk of crack formation exists in the initial period of drying out, when hygroscopic moisture decreases in surface layers only. When tensile stresses reach limit values, a pattern of micro-cracks forms on the round timber surface, which increase with their development, consolidate, forming larger cracks, which finally form a macro-crack, when being combined with other similar cracks. This macro-crack becomes more prevalent and reaches a medullary sheath. It can be assumed that, upon formation of such crack in evenly drying out round timber, internal shrinkage stresses will completely disappear.

If a crack has a small depth, then reduction of stresses will be partial. Further drying out will lead to new stress buildup and further crack development. The crack development process does not end with the alignment of hygroscopic moisture throughout the round timber cross-section.

Among other requirements, a wooden house shall have appearance which complies with modern requirements. Timber rounding allows obtaining a construction material of a proper geometric shape. However, in due course time, house appearance deteriorates due to internal shrinkage stresses and formation of deep cracks. To develop activities for the reduction of the crack formation risk, it is necessary to study changes in the internal stress value of round timber upon drying out.

Study Technique. In this view, the work of Shevchenko V. A. and Feller M. N. (Shevchenko, Feller 1962, 1964) shall be noted. The authors considered a case of hygroscopic moisture distribution in a circular cross-section according to the second-order paraboloid law.

To solve the task relative to the initial drying stage, we accepted moisture distribution according to the sixth-order paraboloid law (Figure 2).

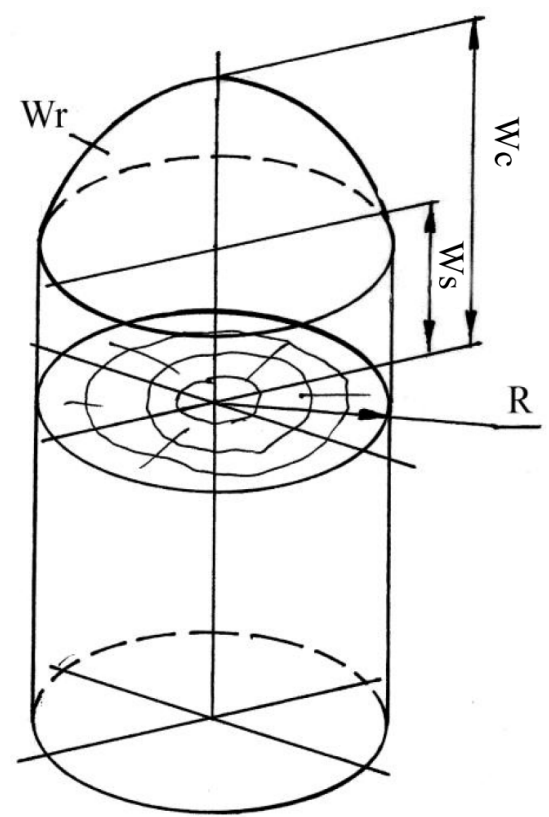

Figure 2. Distribution of hygroscopic moisture hroughout the round timber cross-section

The hygroscopic moisture function will take the following form:

$W=W_{c}-\frac{W_{c}-W_{s}}{R^{6}} \cdot r^{6}$

where Wc, Ws - wood moisture in the center and on the surface of round timber, $\%$.

Internal stresses in wood are conditioned by the hygroscopic moisture variation, anisotropy of the structure and properties in various structural directions.

Assuming that we have an elastic cylindrical body, annual rings of which represent concentric circumferences, and constant elasticities of which do not depend on the wood moisture content, it is possible to consider it to be an orthotropic and cylindrically anisotropic body, the anisotropy axis of which coincides with the longitudinal geometric axis, and radial and tangential axes are perpendicular to it. 
Solving the plane task using elasticity theory methods, we use the following differential equation for an orthotropic and cylindrically anisotropic body (Glukhikh, Akopian, 2010):

$$
\frac{r^{4} \partial^{4} F}{E_{t} \partial r^{4}}+\frac{r^{3} \partial^{3} F}{E_{t} \partial r^{3}}-\frac{r^{2} \partial^{2} F}{E_{r} \partial r^{2}}+\frac{r \partial F}{E_{r} \partial r}=\frac{r^{8}}{100}\left(42 K_{t}-6 K_{r}\right) \frac{W_{c}-W_{s}}{R^{6}}
$$

Where $E_{t}, E_{r}$ are constant elasticities of wood in radial and tangential directions; $K_{t}, K_{r}$ are timber shrinkage factors in radial and tangential directions; $W$ is the function of hygroscopic moisture distribution throughout the round timber cross-section.

General solution of differential equation (2):

$$
F-F_{0}+F_{1}+C_{1}+C_{2} r^{2}+C_{3} r^{1+\alpha}+C_{4} r^{1-\alpha}+\frac{3 E_{t}\left(W_{c}-W_{s}\right) 7 K_{t}-K_{r}}{2352-48 \alpha^{2} \cdot 50 R^{6}} \cdot r^{8}
$$

The circumferential stress can be calculated after finding integration constants and corresponding conversions according to the following equation:

$$
\begin{aligned}
& \sigma_{t}=\frac{\left(K_{t}-K_{r}\right)\left(W_{h}-W_{c}\right)}{100\left(1-\alpha^{2}\right)} E_{t}\left(1-\alpha \frac{R^{1-\alpha}}{r^{1-\alpha}}\right)+ \\
& +\frac{7 K_{t}-K_{r} W_{c}-W_{s}}{49-\alpha^{2} \cdot 100} E_{t}\left(7 \frac{r^{6}}{R^{6}}-\alpha \frac{R^{1-\alpha}}{r^{1-\alpha}}\right)
\end{aligned}
$$

where $W_{h}$ is the wood hygroscopicity limit, \%.

Equation (4) shows that in points of the round timber cross-section contour, the circumferential stress is the same, irrespective of its diameter. Table 1 and Figure 4 below provide stress calculation results according to the obtained equations for the following data: $K_{r}=0.2 \%$; $K_{t}=0.3 \% ; E_{r}=500 \mathrm{MPa} ; W_{h}=W_{c}=30 \% ; W_{c}-W_{s}=1 \%$; $\alpha^{2}=0.5 ; R=5 \mathrm{~cm}$.

Table 1. Changes in stresses along the round disk radius during drying

\begin{tabular}{|c|c|c|c|c|c|c|c|}
\hline & \multicolumn{7}{|c|}{$\mathrm{r}, \mathrm{cm}$} \\
\hline Stress & 0.1 & 0.2 & 1.0 & 2.0 & 3.0 & 4.0 & 5.0 \\
\hline $\begin{array}{c}\sigma_{\mathrm{r}}, \mathrm{kg} / \\
\mathrm{cm}^{2}\end{array}$ & -137.94 & -103.55 & -45.82 & -28.16 & -19.0 & -11.27 & 0 \\
\hline $\begin{array}{c}\sigma_{\mathrm{t}}, \mathrm{kg} / \\
\mathrm{cm}^{2}\end{array}$ & -83.03 & -58.56 & -17.74 & -5 & 4.095 & 22.84 & 76.25 \\
\hline
\end{tabular}

When the hygroscopic moisture variation is $1 \%$, upon initial drying, circumferential stresses reach approximately half of the wood tensile strength in the tangential direction.

Saw kerfes in non-exposed surfaces will not affect the appearance of round timber and, in combination with the technological notch, will allow decreasing surface tensile stress values. This will allow reducing the risk of crack formation on exposed surfaces. Micro-cracks will definite- ly appear, but the prevailing crack (its functions are performed by the cut saw kerf) already exists. It will ensure decrease in tensile stresses on the surface and thereby prevent appearance of another macro-crack.

Thus, cutting of a saw kerf beforehand predetermines the location of the prevailing macro-crack allowing avoiding its appearance on the round timber exposed surface. A macro-crack which forms at the bottom of the saw kerf deepens into round timber. This will not worsen the building appearance.

The issue of crack formation in round timber has not been studied enough, therefore, the depth of saw kerfs, their number and width in the house construction technology are not always determined and are often not substantiated.

At the first stage of solving the task, the even drying-out of round timber is considered upon the absence of the hygroscopic moisture gradient. In this case, the reason of the appearance of internal stresses is anisotropy of the wood structure and properties.

Shrinkage strains in the circular cross-section (without saw kerfs) in radial and tangential directions are inter-related and are not realized completely.

When a saw kerf is cut from the contour to the round timber cross-section center, both radial and tangential shrinkage are freely and fully realized and stresses in external layers are significantly reduced.

It is obvious that there is no need to make lateral saw kerfs to the medullary sheath. Firstly, the torsional and bending stiffness of round timber can be impaired. Secondly, the energy consumption needed to make a saw kerf increases, the production cost of a wooden house will increase as well. Thirdly, the saw kerf depth shall be determined according to the reduction of circumferential stresses on the exposed surface of round timber in the house wall to safe values ensuring the absence of macro-cracks while in use.

Two solutions of crack formation tasks are known. The first one is to select functions which have discontinuity in crack sites. The second one is to select functions which allow meeting conditions on crack margins. Functions shall depend on two coordinates: radial and angular.

If there is a possibility to consider conditions on crack margins, then it is mathematically easier to solve the second task. The first task is more complicated, therefore, the second option was selected.

As in the previous case, the fourth-order differential equation in partial derivatives in polar coordinates served as the basis of the solution (2). In the absence of axial symmetry in the task with the lateral saw kerf, the stress function $F(r, \theta)$ contains components with trigonometric functions of angle cosine $m \theta$.

The numerical solution of the task resulted in obtaining the system of 20 equations with 20 unknown variables, which was solved with the use of EXCEL. Coefficients of unknown variables and free members of equations were found for the same data as in the first part of the task for the entire circle without a saw kerf. 
The solution of the equation for the circumferential stress $\sigma_{t}$ allows obtaining values of this stress in points on the circle contour depending on the saw kerf depth.

For each saw kerf depth value, 20 equations were generated and solved with the use of a computer (depth values: $1 \mathrm{~cm}, 2 \mathrm{~cm}, 3 \mathrm{~cm}, 5 \mathrm{~cm}, 7 \mathrm{~cm}, 9 \mathrm{~cm}, 9.9 \mathrm{~cm}, 10 \mathrm{~cm}$ ). 120 equations were solved with the use of EXCEL.

\section{Research Results}

Table 2. Values of circumferential stresses in points on the contour at $\theta=180^{\circ}$ depending on the saw kerf depth

\begin{tabular}{|c|c|c|c|c|c|c|c|}
\hline Stress, & \multicolumn{7}{|c|}{ Saw kerf depth, cm } \\
\cline { 2 - 8 } $\mathrm{MPa}$ & 0 & 1 & 3 & 5 & 7 & 9 & 10 \\
\hline$\sigma_{\mathrm{t}}$ & 5.935 & 5.642 & 4.88 & 3.86 & 2.47 & 0.93 & 0.021 \\
\hline
\end{tabular}

Calculation results are shown in Figures 3 and 4.

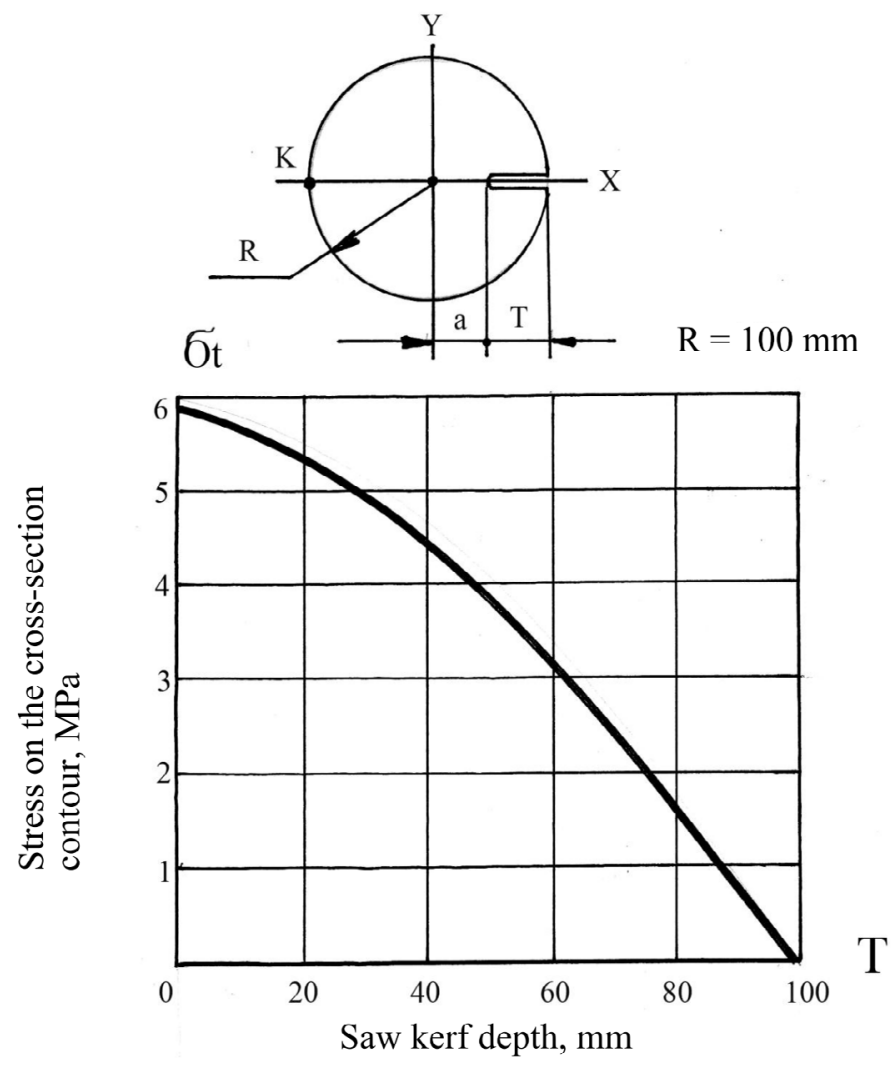

Figure 3. Reduction of the circumferential stress in "K" point with the saw kerf depth increase
Figure 5 shows changes in the circumferential stress $\sigma$ in points on the round timber cross-section contour with the change in angle $\theta$.

With the increase in the saw kerf depth, maximum stresses in the tensile and compressed areas of the cross-section decrease and, in the perfect scenario, when the cross-section of round timber is circular, they disappear completely. This proves the hypothesis that if all annual layers in the cross-section are cut (i.e. there are no intact annular circles), stresses do not appear upon even drying-out.

With the increase of the lateral saw kerf depth, the stress on the round timber exposed surface decreases. At the saw kerf depth equal to a quarter of the round timber diameter, the stress decreases by a factor of 2.5 from 5.935 to $2.37 \mathrm{MPa}$ and, therefore, the cracking risk is reduced, since this stress is less than the wood tensile strength in the tangential direction (Ugolev, 1971).

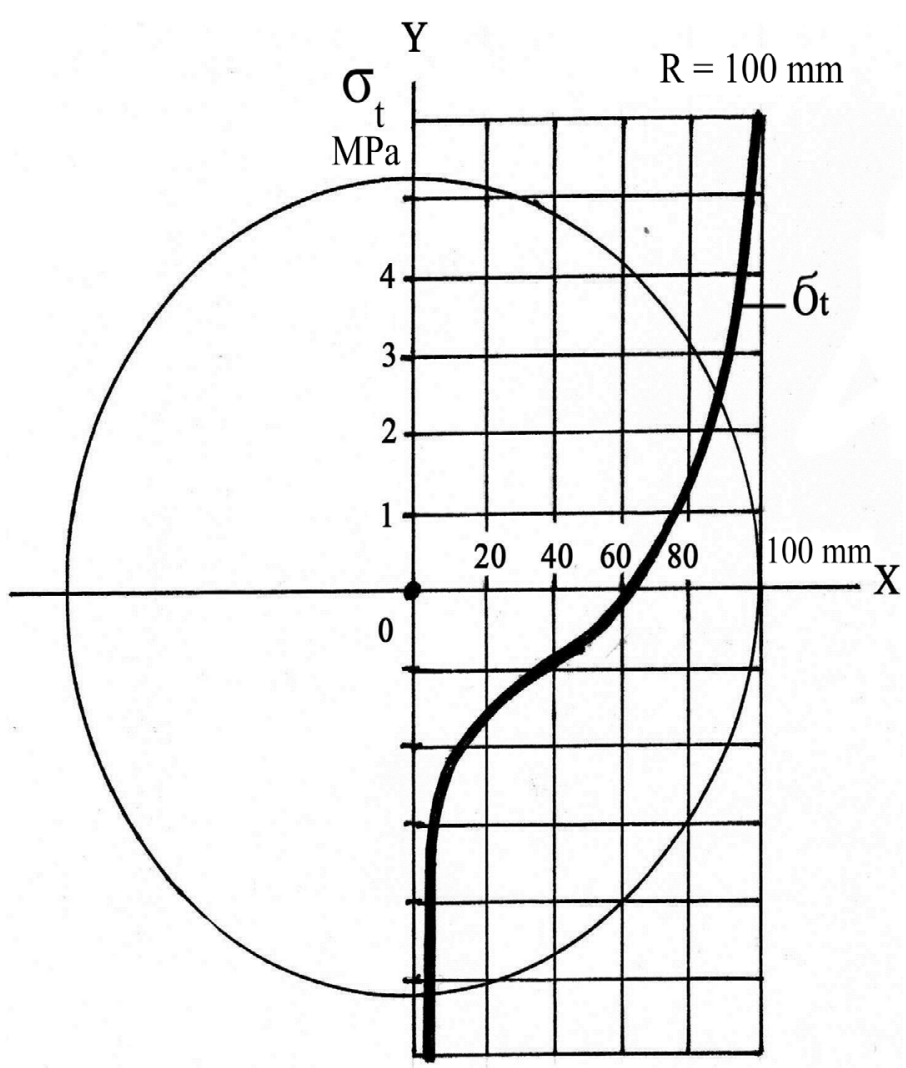

Figure 4. Changes in the circumferential stress along the radius of round timber with the cross-sec-

tion diameter $\mathrm{d}=20 \mathrm{~cm}$ without a saw kerf 


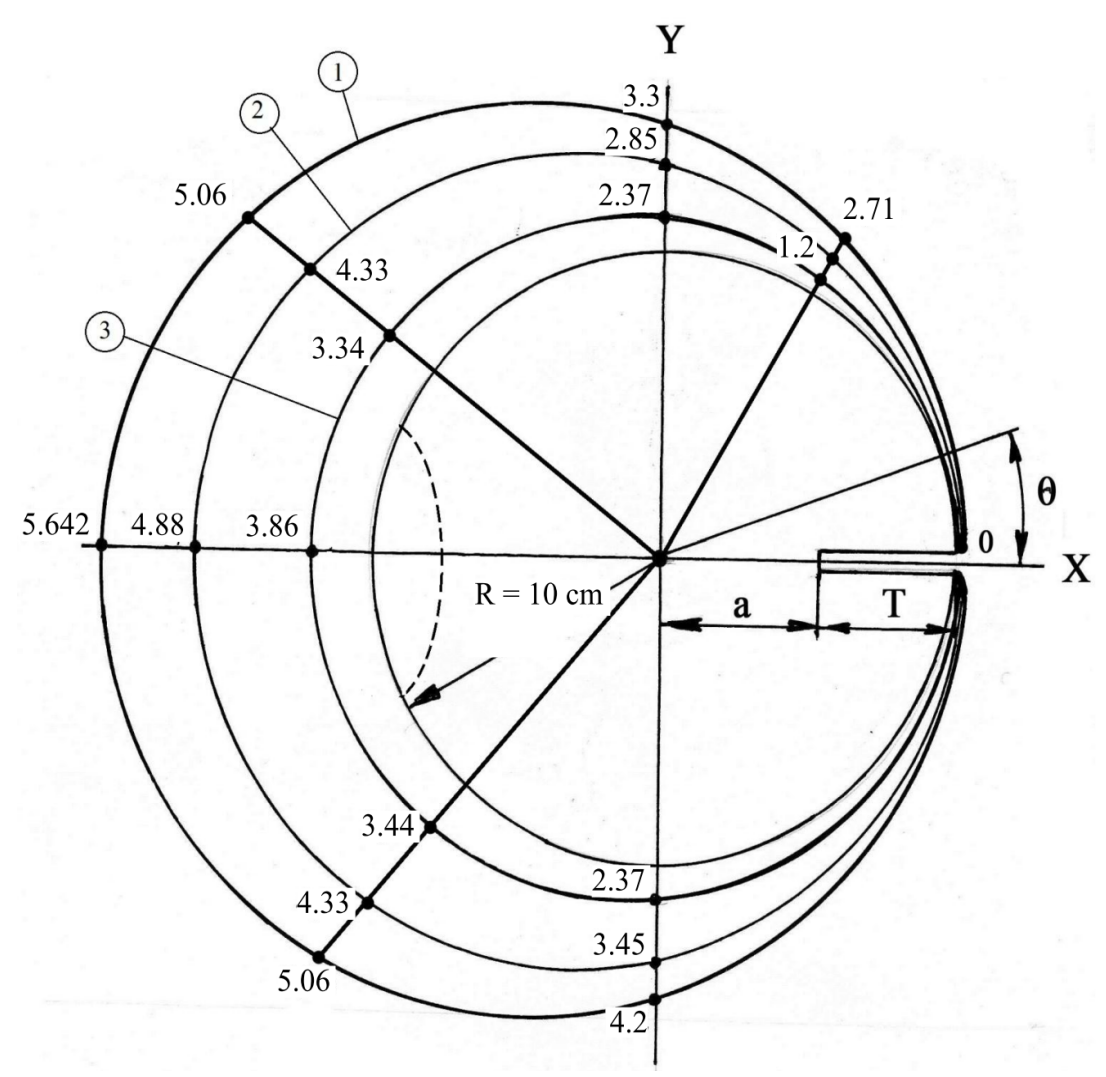

Figure 5. Changes in the circumferential stress depending on the angle $\theta$ at the depth of $1-\mathrm{T}=1 \mathrm{~cm} ; 2-\mathrm{T}=3 \mathrm{~cm} ; 3-\mathrm{T}=5 \mathrm{~cm}$

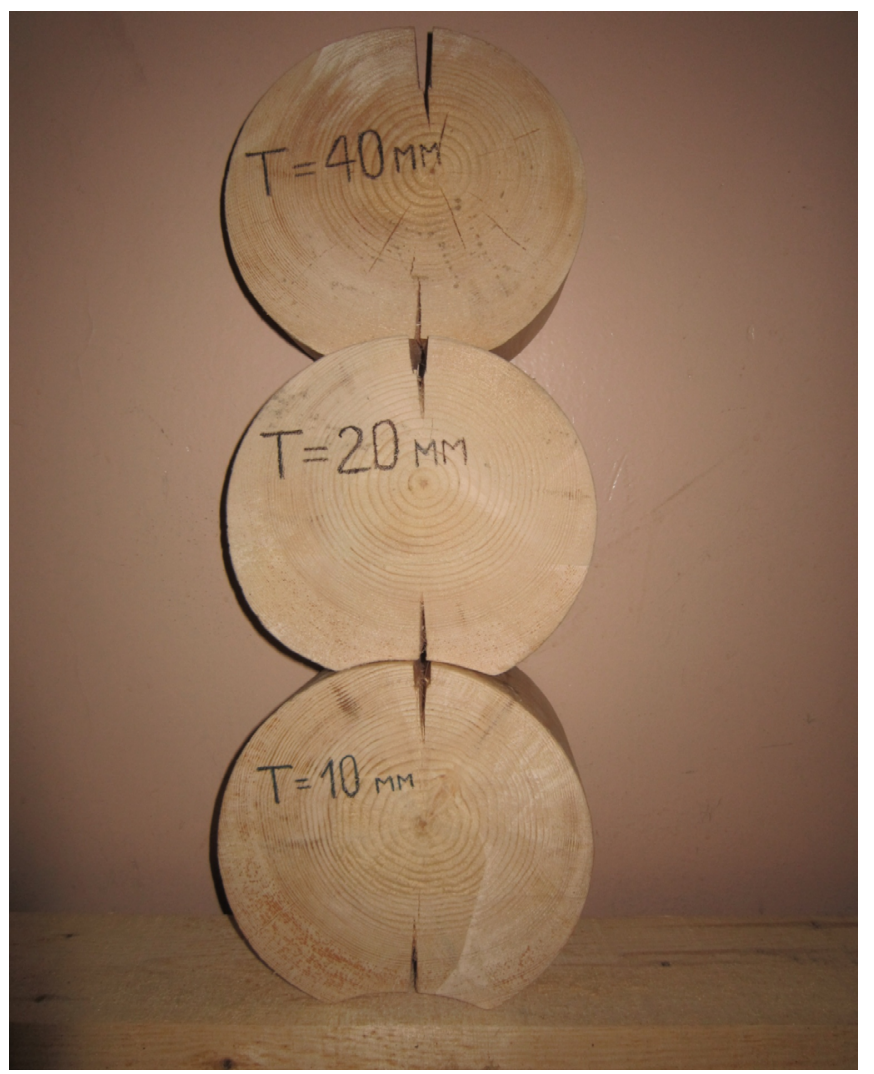

Figure 6. Crack position is defined by the location of the stress concentrator 


\section{Architecture and Engineering Volume 2 Issue 3}

Table 3. Results of experimental studies of crack formation in round timber with a lateral saw kerf

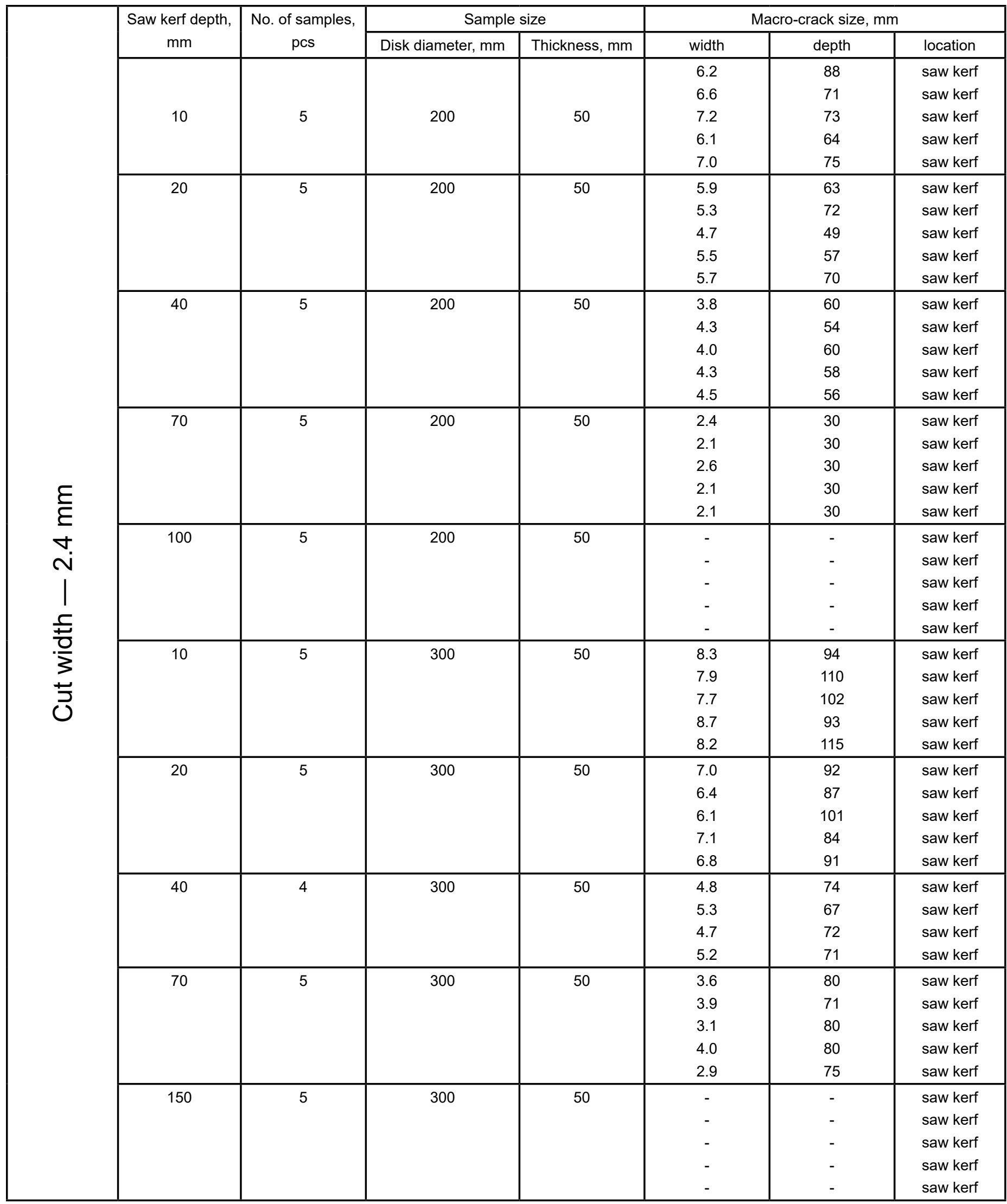


When a crack appears, the stress abruptly decreases. Upon further drying-out of round timber, the stress begins to increase again, and when tensile strength is reached upon tension in the tangential direction, this promotes further crack development. This process is cyclic and it occurs unless the wood moisture reaches the equilibrium value under conditions subjecting round timber.

When there are simultaneously a technological notch and a lateral saw kerf, no visible cracks on the round timber exposed surface were observed (Figure 6).

\section{Conclusion}

Technologically, a lateral saw kerf can be cut in production conditions together with notch making.

The optimal saw kerf depth shall not exceed $35 \%$ of the round timber cross-section radius.

To cut a saw kerf, increase in the energy consumption by $1-2 \%$ is necessary. However, this will result in improved appearance of a building and increase in its service life. 


\section{References}

Chernykh, A. G. (2008). Dereviannoe domostroenie [Wooden house construction]. Saint Petersburg: Saint Petersburg State University of Forestry, p. 343. (in Russian)

Glukhikh, V. N. (2007). Anizotropiia drevesiny kak faktor dlia povysheniia kachestva sushki pilomaterialov [Wood anisotropy as a factor to increase the quality of timber drying-out]. Saint Petersburg: Saint Petersburg State University, p. 160. (in Russian)

Glukhikh, V. N., Akopian, A. L. (2010a). K voprosu ob umen'shenii vnutrennikh napriazhenii usushki v kruglykh lesomaterialakh naneseniem prodol'nykh propilov [On decrease in internal shrinkage stresses in round timber by cutting lateral saw kerfs]. In: Proceedings of the International Scientific and Practical Conference of Young Scientists and Specialists "Modern problems and prospects of sustainable forestry in market conditions". Saint Petersburg: Saint Petersburg State University of Forestry.

Glukhikh, V. N., Akopian, A. L. (2010b). Napriazheniia usushki v kruglykh lesomaterialakh s prodol'nym propilom [Shrinkage stresses in round timber with lateral saw kerfs]. Bulletin of the Saint Petersburg Academy of Forestry, 193, pp. 288-233.

Jlinen, A. (1952). Über die mechanische Schaftformtheorie der Bäume [On the theory of the shape of the tree trunk]. Higher technical school in Finland, vol. 6, p. 51. (in German)

Kuznetsov, A. I. (1950). Vnutrennie napriazheniia v drevesine [Inner stresses in wood]. Moscow: Goslesbumizdat, p. 60. (in Russian)

Lekhnitskiy, S. G. (1956). Anizotropnye plastinki [Anisotropic plates]. Moscow: Fizmatgiz, p. 463. (in Russian)

Sergeyevichev, A. V. (2010). Deformativnost' drevesiny i napriazheniia pri sushke [Increase in the effectiveness of timber rounding through the improvement of the cutting mechanism]. PhD thesis in Engineering. Saint Petersburg: Saint Petersburg State University of Forestry, p. 160. (in Russian)

Shevchenko, V. A., Feller, M. N. (1964). Raschet formoizmeniaemosti drevesiny [Calculation of wood dimensional instability]. Kiev. (in Russian)

Shevchenko, V. A., Feller, M. N. (1962). Rivnjannja vnutryshnyh napruzhen' u derevyny pry ii vysyhanni [Equalizing internal stresses upon wood drying-out]. Bulletin of the Academy of Civil Engineering and Architecture of the UkrSSR, 3. (in Ukrainian)

Ugolev, B. N. (1971). Deformativnost' drevesiny i napriazheniia pri sushke [Strain capacity of wood and stresses upon drying-out]. Moscow: Lesnaya Promyshlennost (Forest Industry), p. 174. (in Russian)

Ugolev, B. N. (1986). Drevesinovedenie s osnovami lesnogo tovarovedeniia [Wood science with the basics of forest merchandizing technique]. Moscow: Lesnaya Promyshlennost (Forest Industry), p. 367. (in Russian) 